\title{
$\begin{array}{lll} & & \end{array}$ \\ Up in the air \\ Italy's space supremo \\ under fire over \\ sketchy budget \\ p327

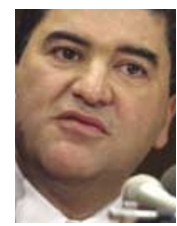 \\ Healthy outlook \\ NIH director Elias \\ Zerhouni aims \\ for the future \\ p329

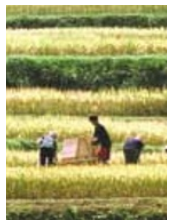 \\ Field work \\ Far East initiatives \\ to foster knowledge of rice genetics \\ p330 \\ 'Mile-deep club' of researchers sets sights on disused gold mine
}

Geoff Brumfiel, Washington

Plans for a new National Underground Science Laboratory in an abandoned gold mine in South Dakota have now gained the backing of both physicists and geologists. But just as scientific interest in the Homestake mine gathers pace, political momentum is waning.

Physicists have already chosen the Homestake mine as their first choice for the new lab (see Nature 410, 292; 2001), on the grounds that it is deeper than the alternatives and so is better protected from cosmic rays, which can interfere with their experiments.

At a National Science Foundation (NSF) meeting, held in Washington on 19-21 September to discuss plans for an underground lab, geologists also gave Homestake their backing. They say that the 2,500-metre-deep mine is ideal for studying geology, hydrology and subterranean bacteria.

For physicists, the site offers a chance to conduct studies such as the Underground Nucleon Decay and Neutrino Observatorya 400,000-tonne water tank designed to detect neutrinos and proton decays. Observing such a decay would provide evidence for theories of supersymmetry, which could help unify grav-

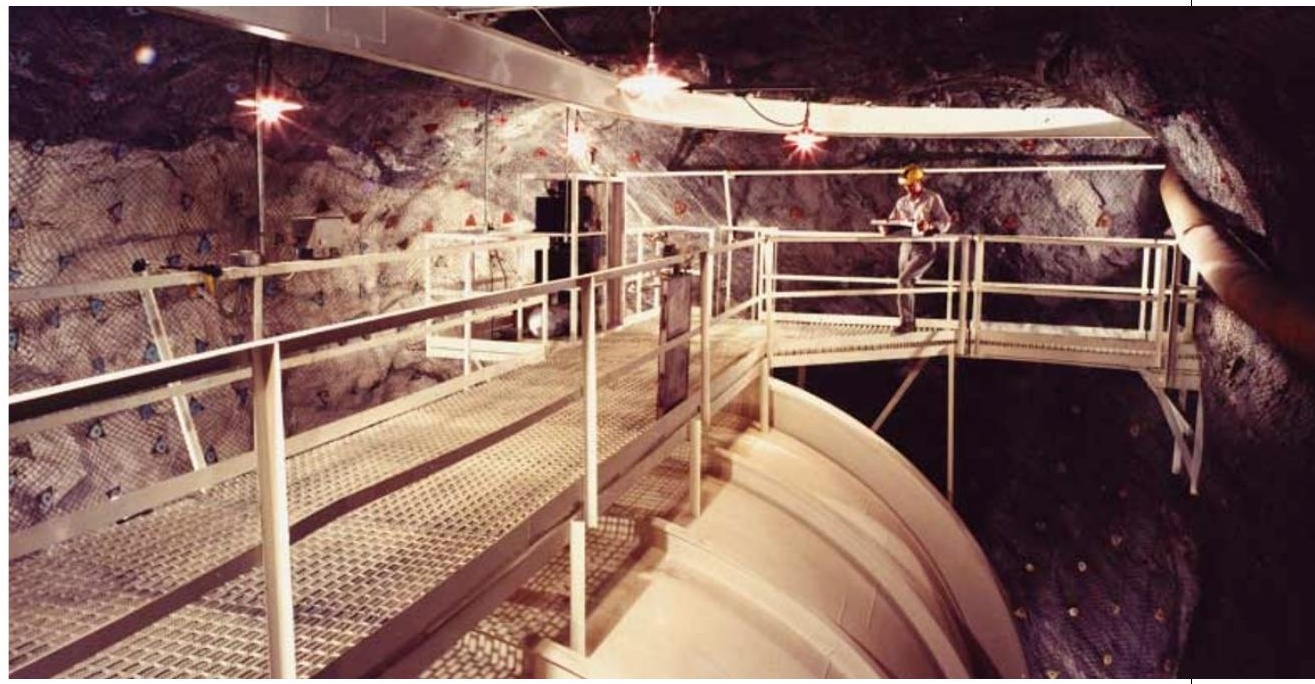

Going underground: Brookhaven National Laboratory's solar neutrino experiment at Homestake.

ity with the three other fundamental forces. Some physics experiments, such as the neutrino studies run by the Brookhaven National Laboratory, already take place at Homestake.

Around 70 of the 300 delegates at last week's Washington meeting were geologists.
One reason for their support is that Homestake offers the potential to study subterranean bacteria that can live for hundreds of thousands of years, says Tullis Onstott, a geomicrobiologist at Princeton University. These bacteria feed on minerals rather than organic

\section{Polar project confirms suspicions about early Universe}

\section{Alison Abbott}

A faint signal from the primordial Universe has provided an important confirmation of theories that describe the period immediately after the Big Bang.

Researchers from the University of Chicago, speaking at the COSMO-02 workshop on particle physics and the early Universe, held last week in Chicago, presented the first evidence of a tiny polarization in the cosmic microwave background radiation. Such a polarization had been predicted by standard inflationary theories, which hold that the Universe underwent a rapid expansion immediately after the Big Bang. "This confirms, almost beyond doubt, that we really have understood the very young Universe," says Simon White, a director of the Max Planck Institute for Astrophysics in Garching, Germany.

The cosmic microwave background dates from some 300,000 years after the Big Bang, at which time the Universe was cool enough for protons and electrons to combine to form atoms. This allowed photons to travel freely through the Universe, as atoms interact less frequently with photons than free protons or electrons do. These photons form the microwave background.

One key prediction about the microwave background - that its temperature varies in different parts of the sky - has already been confirmed. The temperature differences are thought to be the remnant of small density fluctuations that seeded the formation of galaxies (see Nature 411, 880-881; 2001).

Theory predicts that the density fluctuations will also have caused some polarization of the microwave photons - a prediction now confirmed by the Chicago team. They studied 200 days' worth of data taken from two points in the sky by the National Science Foundation's Degree Angular Scale Interferometer radio telescope at the Amundsen-Scott South Pole Station. The effect is slight and has eluded scientists for decades, but the telescope was sensitive enough to identify a polarization that matches the predictions.

Researchers now want to increase the sensitivity of the polarization measurements. Several teams are now focused on this goal, including the consortium that runs Balloon Observations of Millimetric Extragalactic Radiation and Geophysics (BOOMERANG) - a balloonborne telescope that navigates Antarctica. 
compounds, and so could provide clues about early life on Earth. Little is known about them because scientists are rarely able to study them at the temperatures and pressures at which they naturally live.

"There are many questions that need to be answered," says John Parkes, a geomicrobiologist at the University of Bristol, UK. "A deep mine will be very valuable."

Both Republicans and Democrats had originally been keen to back the project in order to win support for their candidates contesting the South Dakota seat in this November's Senate elections.

But with political enthusiasm lessening as attention turns to Iraq, a dispute between the NSF, which is expected to fund and run the lab, and Barrick Gold Corporation, Homestake's owners, could scupper the plans of physicists and geologists. The NSF is adamant that the proposal must undergo peer review, but in a public letter last month, Barrick's vicepresident Patrick Garver stated that the process would take too long. "It appears to us that a final determination is unlikely to be finalized for several years," he said.

Moreover, Congress is reluctant to agree to Barrick's demand that the NSF assumes environmental liability for the lab before the takeover. If an agreement cannot be reached soon, Barrick says it will allow the mine to flood.

Nonetheless, scientists at the Washington conference remained hopeful that Homestake, or perhaps another site, will become a reality. They say they appreciated the chance to discuss one another's fields, and look forward to the possibility of sharing a lab. "To have these kinds of conversations around the lunch table would just be fantastic," says Onstott.

\section{BSE in human tissue fires debate on patient disclosure}

\section{Erika Check}

For the first time, a tissue sample removed in Britain during routine surgery has tested positive for the human form of bovine spongiform encephalopathy (BSE). The find has reopened the debate over whether people found to be incubating the fatal neurodegenerative disease should be informed.

Last week, researchers announced that they had turned up one positive sample of the misshapen protein, or prion, thought to cause variant Creutzfeldt-Jakob disease (vCJD), among 8,318 tonsils and appendices removed from patients in the late 1990 s (D.A. Hilton et al. Br. Med. J. 325, 633-634; 2002). Earlier data from 3,000 samples had returned negative results (see Nature 405, 7; 2000).

From this, the researchers estimate that about 120 out of every million Britons might eventually develop vCJD, thought to be the result of eating meat products from cattle infected with BSE. That number falls within previous estimates, based on epidemiological modelling, of several thousand cases. But, given that the new calculations are based on just one case, the margin of error remains large. "We're not going to jump to any conclusions," says David Hilton of the Derriford Hospital in Plymouth, wholed the team.

Hilton says that testing of further samples under the existing study, in collaboration with the CJD Surveillance Centre in Edinburgh, will continue through next year. And the British government's chief medical officer, Liam Donaldson, adds that a larger tissuescreening study is planned, which may further

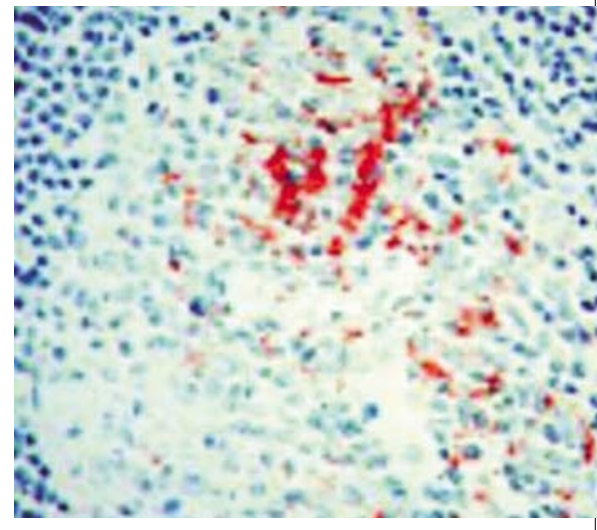

Tell-tale tinge: a red colour betrays the presence of BSE prion in this human appendix sample.

clarify the disease's eventual prevalence.

Meanwhile, Swiss scientists have begun their own screen of tissues from surgery and autopsies. Adriano Aguzzi, a neuropathologist at the University Hospital in Zurich, says doctors will examine thousands of samples over the next decade or so. But whereas the UK survey is anonymous, so that patients who test positive cannot be notified, the Swiss survey will retain patients' details.

"We think the science in the prion field is advancing very quickly, and it's not unlikely that in three or five years' time there will be a way to block the prion from causing disease," says Aguzzi. If therapy becomes available, Swiss test results will be made available; they will also be disclosed to specific patients who request them even in the absence of a cure.

\section{Nanoscale etchings let art lovers read the small print}

\section{Carina Dennis, Sydney}

For Stephanie Valentin, an artist at Sydney's College of Fine Arts, it was a new world to explore. Paul Munroe, a materials scientist at the University of New South Wales in Sydney, found it a rare opportunity to apply a tool commonly used for studying electronic circuits to a biological specimen. The result - a series of micrometre-high words carved into grains of pollen - went on display in Sydney's Stills Gallery on 11 September.

Valentin approached Munroe in her quest to find a method for writing on pollen. He suggested using a focused ion beam miller: a device usually used to etch the surface of electronic circuits. With Munroe's help, Valentin used a narrow beam of gallium ions to carve words on

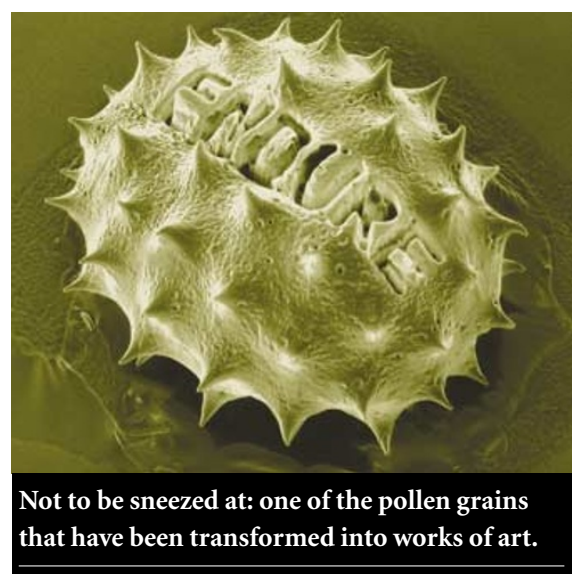

pollen grains with a diameter of around 20 micrometres.

The project has useful scientific spin- offs, as other researchers are interested in using focused ion beam millers to study biological samples. "What is notable is that they were able to use it to etch pollen without destroying it in the process, and with a very high degree of precision and control," says Ian Williams of the Australian National University (ANU) in Canberra, who uses ion beams to analyse geological samples.

"Not much work has been done on biological materials," says Sally Stowe, also at ANU. Stowe plans to use focused ion beams to scrutinize the interface between hard and soft materials, such as titanium implants in bone. The ion beam should allow her to carefully cut away layers of the sample without damaging it. "It's a nanoscale Swiss Army knife," she says. 